\title{
La Santa Hermandad Real y Vieja de Talavera de la Reina
}

Las largas guerras entre moros y cristianos, las contiendas entre los mismos Reyes y las luchas entre Castros y Laras, dejaron los territorios de Ciudad Real, Toledo y Talavera infestados de malhechores que hacían imposible la vida fuera de las murallas de las ciudades, de tal forma que las andanzas y fechorías de los golfines hicieron escribir a Lucio Marineo Sículo estas palabras : “Estaban entonces cruelmente fatigadas muchas ciudades y pueblos de España de muchos y cruelísimos ladrones, de homicidas, de robadores, de sacrílegos, de infinitos insultos y de todo género de delincuentes; que no podían defender, los habitantes de estas ciudades, sus. patrimonios y haciendas de tales criminales, que ni temían a Dios ni al Rey; que no tenían seguras sus hijas ni mujeres, porque había mucha gran multitud de malos hombres de los que unos, dados al vientre $y$ al sueño, forzaban notoriamente casadas, vírgenes $y$ monjas, y otros, crúelmente salteaban, robaban y mataban a mercaderes caminantes y hombres que iban a las ferias; que otros, que tenían mayores fuerzas y mayor locura, ocupaban posesiones y lugares y fortalezas de la Corona Real, y. saliendo de allí con violencia robaban no solamente los ganados, más todos los bienes que podían haber; que asimismo captivaban a muchas personas, ias que sus parientes rescataban no con menos dinero que si los hubieran captivado moros $\mathrm{u}$ otras gentes bárbaras enemigas de nuestra Fém.

En tal estado de cosas, era indispensable iniciar una represión 
ordenada y permanente de aquellos desmanes y depredaciones; asi surgieron las Hermandades, de una de las cuales, de la de Talavera, vamos a ocuparnos, aunque sea someramente, en el corto espacio de este trabajo.

Proviniente de los tiempos de Alfonso VIII y confirmada por San Fernando, mereció la aprobación, regia, entre otros, de Pedro I, Enrique II y Juan II, recibiendo nuevos y valiosos privilegios hasta la época de Felipe II. En realidad, eran tres las Hermandades más importantes de aquella época en Castilla : la de Toledo, Villarreal (hoy Ciudad Real) y Talavera, a las cuales se unían en sus fines el. Maestrazgo de Calatrava. Posteriormente se creó otra en Segovia con los naturales de aquellas tierras y parte de Avila. Altamira habla de las Hermandades de Escalona y Segovia, Escalona y Avila, Plasencia y Avila, a fines del siglo xII, y las de Talavera y Toledo, después de la minoridad de Alfonso VIII.

¿Cuál fué la fecha del nacimiento de esta Santa Hermandad? Pregunta es ésta difícil de contestar con la exactitud de una fecha o con el dato de un Privilegio Real conocido. En el mismo preámbulo de las Ordenanzas de la Hermandad de Talavera, que rigieron hasta su dịsolución, se dice : "... pues ignorándose su origen, por otro medio, que el de antigua tradición, sólo se sabe que en los primeros años, que España logró su felice restauración, del tyrano poder de los sarracenós, estando infestados universalmente los Despoblados, con gente de mall vivir, que entoncés apellidaban Golfines (cuyo nombre corresponde hoy al de ladrones, salteadores), en tanto extremo que llegaron a elegir rey, que les gobernase, y defendiese, apellidado Carchenilla, cuya residencia tenía en los montes que oy circundan a Guadalupe para mayor seguridad de los caminantes, travajadores, haciendas y heredades de los campos, que continuamente experimentaban su extorsión; los cavalleros de Toledo, Talavera y Villa real, hicieron una junta y Hermandad, para perseguir semejante gente".

La "Santa Hermandad Real y Vieja de la Noble Villa de Talavera" tiene, como se ve, un origen muy antiguo, y no dejó de estar continuamente en la palestra en defensa de las honradas gentes de la comarca, pero lo que realmente nos interesa comentar aquil son 
sus Ordenanzas, presentadas en 1746 a la aprobación del Consejc de Castilla y de Su Majestad Católica el Rey Don Fernando VI. Canstan de 51 capítulos (el 44 duplicado) y se presentan al Rey firmadas por D. Gaspar Iváñez Leyba, D. Pasqual Feliz Taravejano, D. Pedro Blas de Mejorada y Dávila, D. Joséph de Ampuero, D. Bernardo Poblete, D. Rodrigo Villarroel y Abalos y D. Pedro de Rivera, autorizándolas el Escribano de la Hermandad don Francisco Joséph Muñoz.

Comenzaban con una bella invocación al Dios, Uno y Trino: "En el Nombre de la Trinidad Suprema, Padre Ingénito, de quien: como de Fuente procede toda la Divinidad, Hijo Sabiduría Eterna, que nació de la boca intelectual del. Padre, como Imagen viva, y clarísimo Espejo de su Divina Esencia, Espíritu Santo, infinito... etcétera". Luego el encabezamiento: "Nos el Cabildo, Alcalde, Regidores y demás Hermanos de la Santa Hermandad Real y Vieja de los Montes y Términos desta muy Noble y Leal Villai de Talavera, estando juntos en nuestro Cabildo, en la Iglesia de Nuestra Señora Santa María de Roque Amador, como tenemos de uso y costumbre..." y la justificación de por qué se procede al estudio y aprobación de las nuevas Ordenanzas "por quanto las Ordenanzas antiguas que han venido de regla a este Cabildo, no pueden observarse las más de ellas, por las novedades de los tiempos...n. Las que se presentaron se basan en "los Privilegios, Executorias, Buenos Usos y Costumbres», de la Hermandad y "en la importancia de su. conservación y perpetuidad, por la necesidad que hay de expurgar, y livertar en todo los tiempos la República desta pestilencia de hombres facinerosos y malos de los que havrá abundancia en el mundo todo el tiempo que huviesse hombres...). Es tan interesante, y at mismo tiempo tan bello el resto del preámbulo de estas Ordenanzas, que nos induce a copiarlo literalmente. Dice así : “...y que el medio más oportuno y conveniente es la unión de Ministros vigilantes, y cuidadosos que son los ojos, pies y manos, con que un Monarca ve, u toca los sucessos, que acaecen en todo su Reyno, y se halla presente a todas sus Provincias distantes, siendo esta disposición tan acertada, que se halla comprobada de infinitos exemplares, no solo Políticos, y profanos, sinó tambien Sagrados; pues 
de aquel célebre Caudillo y Governador del Pueblo de Dios, Moyses, de quien se pudo decir tuvo la virtud de Dios para el govierno, consta, que no solo de.su suegro, Jetro, Sacerdote de Madian, sinó del mismo Dios, fué mandado en dos ocasiones que eligiese Ministros que le ayudasen a llevar carga tan pesada, y a governar tan dilatada multitud de hombres, para lo que él siendo solo no era suficiente, y lo que es mas, el mismo Dios nuestro Señor, cuya ciencia todo lo comprende, cuya inmensidad lo llena y cuyo poder todo io abraza, ha dispuesto el govierno deste mundo, por medio de las Criaturas Angélicas, siendo estos Ministros de Dios, embiados a. la tierra, los Ojos del Inmaculado Cordero, eligiendo entre todos los demás, con especial providencia, el Coro de las Potestades, para que refrenasen el orgullo, y malignidad de los Espíritus aéreos, que vagueando por el mundo, infestan a los hombres con su depravada malicia, y los causan muchos daños, y ruinas, así espirituales como temporales, perturbando su quietud, y sosiego, poniendo tambien a la puerta del Parayso a un Cherubin refulgente, con la espada de llamas, symbolo de la Divina Justicia, para que vibrandola severo, purificase a aquel Lugár Sagrado, y àpartase de él todo hombre pecador, e inmundo. Todo lo qual es irrefragable testimonio de la utilidad, que se sigue a la República, de la conservación desta nuestra. Santa Hermandad...".

Constan las Ordenanzas, como antes decimos, de 51 capítulos, de los cuales el I se refiere a la Capilla de la Hermandad, que era "la Iglesia de Nuestra Señora Santa María, con el título De Roque Amador, en virtud de Donación y Dotación, que de ella le hizo ei Eminentísimo Señor Don Francisco Ximénez de Cisneros, Cardenal de la Santa Iglesia Romana, y Arzobispo que fué de Toledo, para el mayor adorno de nuestra Real Cárcel, contigua a ellan.

En el capítulo II se ordena la creación de una Capellanía en la: dicha Iglesia y que en el Cabildo de la Hermandad que se celebrase el día de la Asunción se nombrara "Capellán cumplidor, a quien por los tercios del año se le han de dar, y pagar, por el Mayordomo, de las rentas deste Cabildo, seiscientos y cinquenta reales de ve$116 n$ ".

Por esta cantidad estaba obligado el Capellán a decir Misa re- 
zada "con precedente toque de campana" todos los Domingos y días de fiesta "por la limosna de quatro reales de vellón que por cada una se le consignan, pero la Misa solemne y vísperas del dia de la Asunción la habría de celebrar, como el funeral anual por los Hermanos, "costeándolo todo a sus expensas".

Los Hermanos no podían exceder de sesenta, cuidándose de que "no sea recibido por Hermano alguno que no tenga veinte años de edad o fuese casado; y que sea vecino o natural desta Villa, con residencia en ella, y tenga Armas y Caballo, y la demás aptitud para servir en las salidas que se le destinasen". Una condición fundamental hubo al principio de la existencia de esta Santa Hermandad y era que tuviesen los Hermanos posada de Colmenas, propia y poblada, a lo menos con el número de sesenta, porque por lo visto fué éste, como dicen las propias Ordenanzas, en su capítulo IV, cel principal objeto que impidió a la unión y constitución de las tres Hermandades"), sin duda con el fin de proveer al "mayor augmento y conservación de dicho comercion. No obstante, la Hermandad, en épocas posteriores, no tenía ya "posadas de coimenas", entre otras cosas, "por la decadencia deste trato y otras calamidades, están desmontadas y reducidas a tierras labrantías, y su misión fundamental y el principal objeto deste Cabildo, debe dirigirse a la persecución y extirpación de vandidos y malechores» (capítulo IV).

La recepción, previa presentación del Memorial del aspirante a Hermano, había de acordarse por el Cabildo en una de las reuniones o Cabildos Generales del $10^{\circ}$ de mayo y del 15 de agosto, y era de un rigorismo ritual severo: El Alcalde más antiguo nombraba a dos Hermanos que salían a recibir al aspirante y la introducción en la Sala Capitular "en donde estará el Cabildo sentado» a presencia del Alcalde citado, que le recibirá juramento, "por Dios y una Cruz», de cumplir con las obligaciones de Hermano y no permitir que padezca menoscabo la jurisdicción y privilegios de la Hermandad. Juraba, además, defender el Misterio de la Inmaculada Concepción de Nuestra Señora la Virgen María. Prestado el juramento se vuelven a sus asientos los Comisarios que le recibieron y el escribano lleva al nuevo Hermano al lugar que le corresponde 
y le pone en posesión. En este momento “se le entregará al nuevo Hermano un testimonio por nuestro Escrivano de su admisión, con expresión de las Facultades que cómo tal tiene para poder prevenir, hacer Sumarias, prender y emvargar en todos y cualquier Causas". El recipendario pagaba lo que se llamaba la "propina", que eran cuatro reales de vellón y una libra de cera blanca para el culto de la Virgen. Los Cabildos tenían lugar en "la Iglesia de Nuestra Señora sita en la Hermita de Roque Amadorn, y en ellos se elegían los cargos rectores, que eran los siguientès: Dos Alcaldes, dos Regidores, un Quadrillero Mayor, Fiscal, Procurador de Pobres, Mayordomo y Alcayde. Los Escribanos los nombraba el Rey.

Parece ser que el procedimiento para nombrar estos cargos varió. con el transcurso del tiempo, pues se dice "que experimentando los graves inconvenientes de pandillas, poliaciones y otros que nos han demostrado la malicia de los tiempos, dispúsose que la elección de Oficios se haga por suertem. Ei día señalado para esta elección era precisamente el 15 de agosto, día de la Asunción, y en este acto solemne cada Alcalde proponía en cédulas separadas los nombres de cuatro Hermanos ude los que tuviere por más proporcionados, para sucederle en el empleo", y por el Escribano se introducían las ocho cédulas dobladas, en una urna, y en otra "seis blancas, y las dos con nombre escrito de Alcalde". Después de removerlas se iban sacando por el Portero una cédula de una urna y otra de otra hasta que salían los dos Alcaldes.

Los Oficios de Regidor se elegían en forma parecida, pero la propuesta de nombres se hacía por los Alcaldes (un nombre cada uno) y por los Regidores (dos cada uno). La propuesta de Quadrillero Mayor correspondía hacerla mediante lista de cuatro nombres por los Alcaldes, y al Quadrillero (dos nombres). Señalaban las Ordenanzas una serie de incompatibilidades e incapacidades para desempeñar los dichos Oficios, siendo notables entre las primeras la del cargo de Alguacil Mayor de la Villa, como el de Quadrillero Mayor, y entre las segundas la de los que uejercieran oficio mecánicon.

El Fiscal, que era a la vez Archivero, Contador y Tenedor del Sello, se elegía por tres años. Los Escribanos debían ser nombrados 
por el Rey, pero una de las Escribanías (eran dos) pertenecía "por juro de heredad» en la época, en que se aprobaron las Ordenanzas que comentamos, a don Francisco Joseph Muñoz y la otra "estaba sin uso por no haber providenciado Su Magestad». Ei salario anual de estos cargos eran 550 reales de vellón "más los agasajos de estilon. Los cargos restantes eran gratuitos, pero al finalizar el Cabildo General, que se celebraba el 15 de agosto, "en atención a el ningun salario, ni gratificación que da a sus Individuos habia la inmemorial costumbre de darles un refresco general a todos los presentes, de bebidas y vizcochos".

También en el Capítulo XXXII se hace referencia al "ragasajo. que se ha de hacer a los Oficiales, en las Pasquas" y que consistía en que se diera "a los Alcaldes dieciseis pares de perdices, ocho a cada uno por la Pasqua del Nacimiento del Redemptor: A los Regidores seis pares $x$ cada uno: A el Quadrillero Mayor otros seis pares; Al Fiscal y Escrivanos, seis pares a cada uno; Al Capellan tres y al Mayordomo otros tres pares». Luego, por la Pascua de Resurrección, era también. costumbre dar a cada Alcalde un carnero y un cordero; a cada Regidor medio carnero y un cordero; ai Quadrillero Mayor, Fiscal y Escribanos, a cada uno, medio carnero y un cordero, y ai Capellán y Mayordomo, a cada uno, un cordero.

No podemos, en el limitado espacio de este trabajo, entrar a estudiar aspectos muy importantes de estas Ordenanzas de la Santa Hermandad Real y Vieja de Talavera, pero no quisiéramos dejar de evocar una escena que su lectura nos trae a la imaginación. No sería quizá demasiado frecuente, pero no por ello menos impresionante. Teniendo la Santa Hermandad jurisdicción propia, era natural que, con cierta frecuencia, hubiese alguna que otra condena a muerte, y entonces tenía lugar una severa e intimidante ceremonia. Confirmada la sentencia de pena capital por la Chancillería de Valladolid, los Alcaldes juntan Cabildo y toman las providencias def́ caso. Tres días antes de la ejecución el Alcalde de la Causa, con el Escribano, se traslada a la cárcel, y ante los religiosos que han de asistir al reo, le notifica la sentencia "para que, aprovechando el corto tiempo que le queda de su vida, prevenga su muerte cor 
la mejor disposición". El día de la ejecución se forma el triste cortejo con aparato de "gran función". Inician la marcha las "Cofradías de estilon; detrás, a caballo, ocho Hermanos de los destinados aquel año para hacer las salidas; luego los demás Hermanos, también a caballo; tras de ellos, cuatro saeteros a pie "con su arco y flechas y ropas verdes uniformesn. Ahora viene el reo con los religiosos que le asisten, seguido por el Quadrillero Mayor, a quier lo entregaron. los Alcaldes, y a su izquierda, el Escribano que va a dar fe de la ejecución. Cierran marcha Hermanos a caballo con el estandarte al frente, y detrás, el Alcayde. Se pregonan por las calles los delitos de la causa y la pena impuesta por ellos, haciendo un alto en la calle del Perdón, en donde no se podían pregonar delitos ni penas, y se llega al lugar de la ejecución. Mientras se lleva a cabo estarán reunidos en la Sala de Audiencia de la cárcel los Alcaldes, el Fiscal y el otro Escribano hasta que, cumplida ia ley, el Quadrillero Mayor lo participa así a los que, reunidos, esperan y el Escribano lo certifica. Si la pena fuese cuartear al reo, la cabeza y los cuartos de éste serán portados por el Quadrillero y el Escribano a los sitios de costumbre, en donde los mortales despojos se expondrán al público.

Como se ve, a través de las Ordenanzas de la Santa Hermandad de Talavera se puede vislumbrar bastante de la vida de los tiempos que fueron, en los cuales de todo hubo, y hasta por haber hubo la oposición de la Dignidad Arzobispal de Toledo, "a quien privativamente pertenecía la Jurisdicción, Señorío y Vasallaje de la Villa de Talavera", a que se aprobaran las citadas Ordenanzas por "perjudiciales a la Jurisdicción Ordinarian en algunos puntos, con motivo de lo cual hubo pleito ante el Real Consejo.

Se oponía el Cardenal porque whecho el maduro examen que se requería se havia encontrado que eran perjudiciales a la Jurisdicción Ordinarian algunos de los extremos que las Ordenanzas -con-. tenían. Así, alegaba el Arzobispo, que el privilegio concedido a la Hermandad en el año 1652 "para traer Varas de Justicia los Alcaldes, Quadrillero Mayor y demás Oficiales, dentro y fuera de la Villa de Talavera, en todo tiempo del año, se hallaba estar este sirı uso, porque lo que se había observado después de dicha concesión 
era que en el día quince de agosto de cada año se juntaba la Hermandad a hacer Elección de Oficios, y entonces los Alcaldes, Quadrillero Mayor y demás Oficiales, concurrían con sus Varas Altas ; y lo mismo el día siguiente, en señal de posesión y exercicio de Jurisdicción, sin que en lo restante del año volviesen a sacar las expresadas Varas". A ello contestó la Hermandad que "se sirviese tener presente que para esto no necesitaba su parte compra específica de la dicha facultad" y, sobre todo, "la verdad notoria de estar pagando, sin atraso alguno, los Quindenios respectivos a ellan.

Se oponía también el Cardenal a que la Hermandad conociera de los delitos cometidos en poblado y. sostenía que, aun en el caso de que los autores de ellos salieran al campo, la misión de la Santa Hermandad fuese “la aprehensión de sus Personas y Bienes para entregarlos a la Jurisdicción Ordinarian.

Decía también la oposición del Arzobispo que "habiendo cesado los Colmenares, y reducídose a tierras labrantíos, aun cuando en lo primitivo hubiesen tenido algún Privilegio (que negaba) cesaran las Posadas de colmenas, Colmeneros y demás que refería el expresado Capítulon y, por lo tanto, estimaba que no debía haber fueros y privilegios para los Hermanos "por ser todo Privilegio odioso a cualquier Universidad, además de que redundaría en perjuicio de la Jurisdicción Ordinarias.

Y así seguía la Dignidad Arzobispal oponiéndose, en nombre de la Jurisdicción Ordinaria, a diferentes Capítulos de las Ordenanzas de la Santa Hermandad Real y Vieja de Talavera ; pero el Real Consejo, por auto de 13 de septiembre de 1746, las aprobó con ligeras modificaciones como, por ejemplo, en lo que al uso de Varas se refería "con tal de que fueran Varas Altas y no Bastones". $\mathrm{Y}$ así siguió rigiendo aquel ordenamiento legal hasta que Isabel II, por Decreto de 7 de mayo de 1835, dịsolvió las "Santas, Reales y Viejas Hermandades denominadas de Ciudad Real, Talavera y To ledo, así como los Tribunales privilegiados de las mismasn.

Jaime Pereira García,

Secretario de $1 .^{a}$ categoría de Administración Local

NorA. - Las palabras cuya ortografia difiere de la actual están transcritas literalmente. 